\title{
8chan, a Twitter-Fossil: A post-digital genealogy of digital toxicity
}

\author{
Susana Gómez Larrañaga \\ University of Greenwich \\ London, UK \\ sg8504f@gre.ac.uk
}

\section{INTRODUCTION}

The continuous remote communication between consumer media devices and server farms eases the spread of toxic ideologies and distorted perceptions of the world. This concealed and instantaneous exchange of data relies on an industrial infrastructure, which is in turn reliant on the harvesting of minerals - including rare-earth materials - and fossil fuels that make and power computational hardware. Within the software infrastructure of the Network, hyperlinks operate as veins, circulating and amplifying the flow of toxic data. This flow is fundamentally driven into the mainstream by the major online platforms (YouTube, Twitter, Facebook and Google) whose algorithms seek the maximisation of human interaction. Anti-social content in less prominent websites is also sustained and monetised by those tech companies providing vital online infrastructure - web hosting, DNS registration and content delivery services, thus playing a crucial role as enablers of human toxicity. The toxic pervasiveness of data relies on the nature of the digital network that inherently encourages the proliferation of "digital debris" (Gabrys 2012; Steyerl 2017). Can a post-digital artistic epistemology shed light on the genealogy - the materiality, the algorithms, the socio-politics - of the toxic layers of digital media?

8chan: A Twitter-Fossil is a case study for the processes, which enable the amplification of toxic ideologies within the Internet. Through the construction of an artwork or a "social-media-fossil" concealed agencies, both human and more-thanhuman, are brought to light by recording and visualising the sedimentary traces left by a system of human, algorithmic and mineral interaction. This is a reflection on the "deep" entanglement between social and "natural" processes. Through materialising and analysing the archives - including textual data - of a creative data visualisation working with the Twitter API, key actors within a multi-layered narrative of digital toxicity are exposed.

\section{A CASE STUDY: 8CHAN: A TWITTER-FOSSIL}

8chan, A Twitter-Fossil; is a case study for the more-than-human processes - microcomputational processes of data streams, the Twitter algorithm and the affordances of the Twitter interface - which enable the amplification of toxic ideologies within the internet. The work is a tactical response to day-to-day events - by observing the socio-collateral events of online activity, links between the human and digital realm are unravelled. As online content impacts upon the human psyche, can the reverse engineering of a digital object articulate a deeper understanding of the relations between algorithms and socio-political structures?

Sedimentation operates as a methodological framework to visualise the inherent proliferation of data streams and forensically analyse the nonlinear strata of digital data - hyperlink and network analysis are employed to provide context to the archived textual content. By designing a processual application that draws directly from the Twitter API alongside cyanotype printing, the artwork is a "social-media-fossil" challenging anthropocentric perspectives of agency. The materialised "digital object" operates as a politico-critical object addressing the invisible entanglement between the socio-political realm, algorithms and minerals. Accordingly, the work reflects on the conflation of two philosophical concepts: "geo-social formations" (Clark \& Yusoff 2017) and "media-fossil" (Parikka 2015), drawing attention to the geological genealogies and legacies of (human) social life geo-social formations (ibid) - and of digital media media-fossil (ibid). 


\subsection{Data visualisation: a trace of past relations}

On the 3 August 2019, a domestic terrorist attack was perpetrated at El Paso, Texas, targeting the Hispanic community, leaving a toll of 22 fatalities and 20 other people injured. Minutes before the attack, the perpetrator uploaded an "eco-fascist" and white-supremacist manifesto to the messageboard 8chan. The website has a track record of white-supremacist mass shootings, where anons (a name for users in 8chan where neither accounts nor names are necessary for posting, posts are identified by a number) operated in a similar fashion. 8chan is known for its gamification of mass violence where references to beating "high score" are made, implying high death counts (Evans 2019).

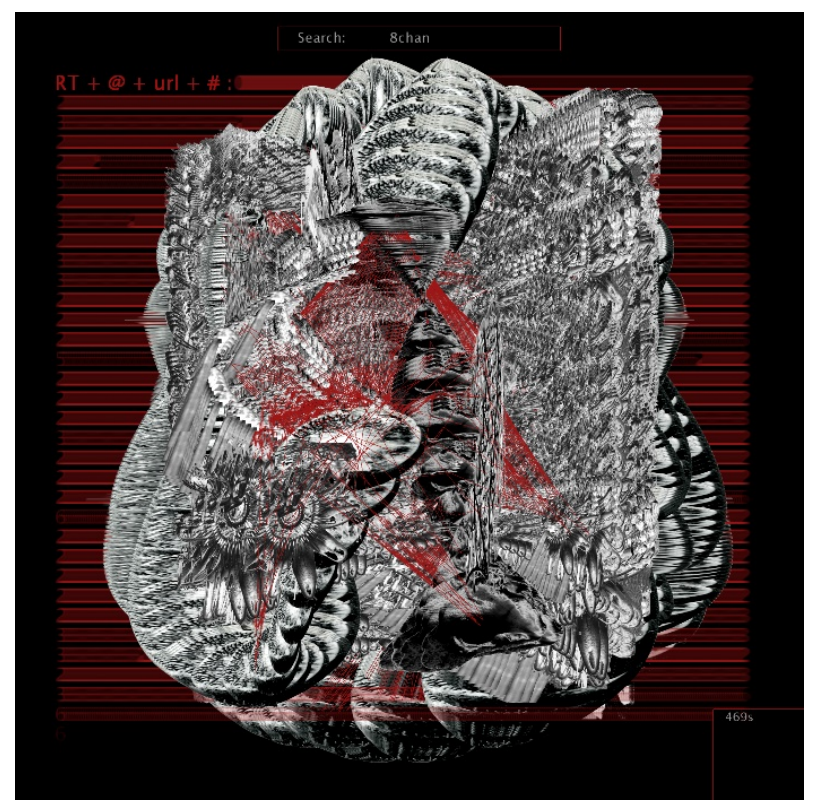

Figure 1: Processing application interface after running for 469 seconds. The lines behind the form are made of the number of relations in each tweet as Pure Data counts them.

Built in Processing and Pure Data, a creative data visualisation responded to the proliferating flow of information across Twitter in the wake of the attack. The data visualisation generated a quasi-organic form from the interactions and spread of data that contained the text 8chan. Formed as the result of the accumulation of past relations (the Processing application responded to the sum of retweets + mentions + urls + hashtags, within each tweet) the form continually builds upon the traces of its own history. Bred by digital memory, the self-consuming "being" articulates its genealogies and legacies: the pervasiveness of toxic ideologies and the evergrowing carbon footprint of "the Cloud" which sustains them. The duality of this relationship is articulated by Parikka's (ibid) concept of medianatures:
"[D]ouble bind of media and nature as coconstituting spheres, where the ties are intensively connected in material and nonhuman realities as much as in relations of power, economy, and work" (ibid, p.14)

\subsection{A 'social-media fossil': more-than-human memory}

Screenshots of (the $30 \mathrm{~min}$ execution) of the creative data visualisation were periodically archived. A selection were then turned into sunprints (cyanotypes). The cyanotypes displayed the stream of tweets filtered by the processing application, alongside the "sentient" entity as it reacted to them.

In order to analyse these 'more-than-human archives' and unveil the plurality of perspectives within the tweets, an investigation of the archived text was conducted by employing hyperlink and network analysis. Through this investigation several techno-socio-political layers which enable and contribute to the amplification of toxic content were uncovered: the insufficient moderation policies of Twitter, Youtube and Facebook (Ghaffary, Molla \& Stewart 2019); US governmental online policies (Wong 2019); the monetisation of hate speech and racism by the hundreds of tech companies providing web hosting, DNS registration and content delivery services to websites including this kind of content (Sankin 2019), including Facebook (Legum 2019a); the lax moderation procedures of 8chan; its long history, and gamification, of violence (Roose 2019; Wong 2019); the rise of domestic terrorism and Trump's government counterproductive removal of grants programs towards its investigation (Barret 2019; Legum 2019b); or, Trump's own contribution to USA's white supremacism (Legum 2019b).

Contemporary and historical articles converge within the hyperlinks of the tweet content. The stratification of tweets reflects Chun's (2007) conceptual analysis of digital memory: the nonsimultaneity of the new, and enduring ephemerality. Searching online for the tweets threads, some tweets are now unreachable and some of the involved accounts appear to had been suspended. The archives become evidence of this enduring ephemerality, addressing a precise moment in time. When searching for these tweets in Google, the search engine often provides only dead links, acknowledging the missing data. In a geological metaphor, Google lists and the application archives are 'trace fossils' - a petrified imprint of biological activity - as their interface captured the now absent data. 


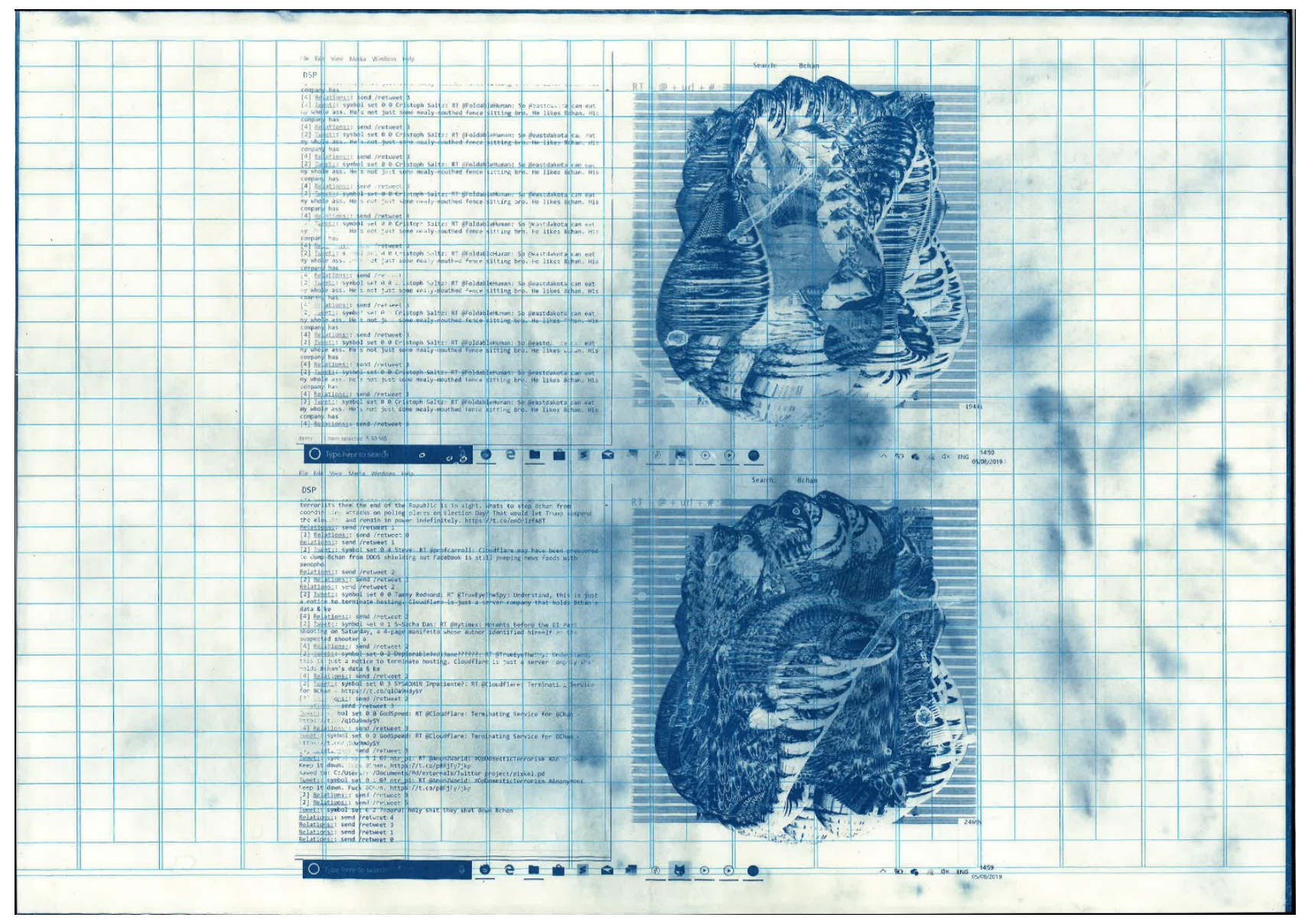

Figure 2: 8chan: A Twitter-Fossil. Cyanotype on paper, 42 × $29.7 \mathrm{~cm}$. Two application archives from 14:50 and 14:59 (GMT), 5 August 2019.

The sunprints or "social-media fossils" operate as material witnesses (Schuppli 2016) to the entanglement of human and non-human forces, by materialising a more-than-human sediment of human, algorithmic and mineral interaction. Sensitive to UV light, these "social-media fossils" operate in a tension that constructs memory through decay, releasing "abject" memories (DeSilvey 2017) that operate outside technohuman systems of value and control. In Finite Media (2017), Sean Cubitt states that the data environment enables the mass instrumentalisation of the material world through the assimilation of human knowledge into countable and exchangeable units, a statement that resonates with Gabrys's reflection on the nature of electronic memory:

\begin{abstract}
"Archivable data is calculable data. This is the other critical component of electronic memory: not only does store, but it also programs material for operation" (Gabrys 2017, p. 110)
\end{abstract}

Through a volatile materialisation the resultant digital archives are turned into political-critical objects of resistance against the concealed structures of power and violence of "the Cloud" (Hu 2015). 8chan: A Twitter-Fossil not only exposes but accounts for the multiple actors that enable the amplification of toxic ideologies online, an intricate stratification of offline and online co-dependency.

\section{REFERENCES}

Barret, D. (2019) FBI faces skepticism over its efforts against domestic terrorism, The Washington Post, 5 August 2019.

https://www.washingtonpost.com/nationalsecurity/fbi-faces-skepticism-over-its-anti-domesticterror-efforts/2019/08/04/c9c928bc-b6e0-11e9b3b4-2bb69e8c4e39 story.html (retrieved 2 March 2020).

Clark, N. and Yusoff, K. (2017) Geosocial Formations and the Anthropocene. Theory, Culture \& Society, Special Issue, 34 (2-3): pp.3-23.

Chun, W. H. K. (2008) 'The Enduring Ephemeral, or the Future Is a Memory', Critical Inquiry, 35 (1) (Autumn 2008), pp.148-171. doi: 10.1086/595632

Cubbit, S. (2017) Finite Media: Environmental Implications of Digital Technologies. Durham: Duke University Press. 
DeSilvey, C. (2017) Curated Decay: Heritage Beyond Saving. Minneapolis, London: University of Minnesota Press.

Evans, R. (2019) 'The El Paso and The Gamification of Violence', Bellingcat: the home of online investigations, 4 August 2019.

https://www.bellingcat.com/news/americas/2019/08 104/the-el-paso-shooting-and-the-gamification-ofterror/ (retrieved 2 March 2020).

Gabrys, J. (2011) Digital Rubbish: A Natural History of Electronics. Ann Arbor: University of Michigan Press.

Ghaffari, S., Molla, R. and Stewart, E. (2019) 'Here's how Facebook, YouTube, Twitter, and 8chan handle white supremacist content', Vox: Recode, 4 August 2019.

https://www.vox.com/recode/2019/8/4/20753951/elpaso-dayton-shooting-8chan-twitter-facebook (retrieved 2 March 2020).

Hu, T-H. (2015) A Prehistory of the Cloud. Cambridge, MA: MIT Press.

Legum, J. (2019a) EXCLUSIVE: How money flows from Amazon to 8chan, Popular Information, 13 May 2019. https://popular.info/p/exclusive-howmoney-flows-from-amazon (retrieved 2 March 2020).
Legum, J. (2019b) 'White Terrorism', Popular Information, 5 August 2019.

https://popular.info/p/white-terrorism (retrieved 2 March 2020)

Parikka, J. (2015) A Geology of Media. Minneapolis \& London: Minnesota Press.

Rose, K. (2019) 'Shut the Site Down', Says the Creator of 8chan, a Megaphone for Gunmen, New York Times, 4 August 2019.

https://www.nytimes.com/2019/08/04/technology/8c han-shooting-manifesto.html (retrieved 2 March 2020).

Sankin, A. (2019) 'The Dirty Business of Hosting Hate Online', Gizmodo, 16 July 2019 (edited 7 November 2019). https://gizmodo.com/the-dirtybusiness-of-hosting-hate-online-1836286885 (retrieved 2 March 2020).

Schuppli, S. (2016) 'Dirty Pictures', in M. Belina, M. (ed.), Living Earth: Field Notes from the Dark. Ecology Project 2014 - 2016. Amsterdam: Sonic Acts Press.

Steyerl, H. (2017) Duty Free Art: Art in the Age of Planetary Civil War. New York: Verso.

Wong, J. C. (2019) '8chan: the far-right website linked to the rise in hate crimes'. The Guardian, 5 August 2019.

https://www.theguardian.com/technology/2019/aug/ 04/mass-shootings-el-paso-texas-dayton-ohio8chan-far-right-website (retrieved 2 March 2020). 